\title{
Oxidative cycloaddition of hydroxamic acids with dienes or guaiacols mediated by iodine(III) reagents
}

\author{
Hisato Shimizu ${ }^{1}$, Akira Yoshimura ${ }^{2,3}$, Keiichi Noguchi ${ }^{4}$, Victor N. Nemykin ${ }^{5}$, \\ Viktor V. Zhdankin ${ }^{2}$ and Akio Saito*1
}

\section{Letter}

\section{Address:}

${ }^{1}$ Division of Applied Chemistry, Institute of Engineering, Tokyo University of Agriculture and Technology, 2-24-16 Naka-cho, Koganei, Tokyo 184-8588, Japan, ${ }^{2}$ Department of Chemistry and Biochemistry, University of Minnesota, Duluth, MN 55812, USA, ${ }^{3}$ The Tomsk Polytechnic University, Tomsk 634050, Russia, ${ }^{4}$ Instrumentation Analysis Center, Institute of Engineering, Tokyo University of Agriculture and Technology, 2-24-16 Naka-cho, Koganei, Tokyo 184-8588, Japan, and ${ }^{5}$ Department of Chemistry, University of Manitoba, Winnipeg, MB R3T 2N2, Canada

Email:

Akio Saito* - akio-sai@cc.tuat.ac.jp

* Corresponding author

Keywords:

acylnitroso; benzoquinone; cycloaddition; dearomatization; iodine(III)

\author{
Beilstein J. Org. Chem. 2018, 14, 531-536. \\ doi:10.3762/bjoc. 14.39
}

Received: 25 December 2017

Accepted: 16 February 2018

Published: 28 February 2018

This article is part of the Thematic Series "Hypervalent iodine chemistry in organic synthesis".

Guest Editor: T. Wirth

(C) 2018 Shimizu et al.; licensee Beilstein-Institut.

License and terms: see end of document.

\begin{abstract}
[Bis(trifluoroacetoxy)iodo]benzene (BTI) and (diacetoxyiodo)benzene (DIB) efficiently promote the formation of acylnitroso species from hydroxamic acids in the presence of various dienes to give the corresponding hetero-Diels-Alder (HDA) adducts in moderate to high yields. The present method could be applied to the HDA reactions of acylnitroso species with $o$-benzoquinones generated by the oxidative dearomatization of guaiacols.
\end{abstract}

\section{Introduction}

The hetero-Diels-Alder (HDA) reaction of $N$-acylnitroso species with dienes provides the facile and highly stereoselective synthesis of 1,2-oxazines, which have been widely recognized as useful synthons in the synthesis of biologically active natural products [1]. Generally, in the presence of dienes, acylnitroso species are in situ generated from hydroxamic acids with oxidants due to their instabilities (Scheme 1, route a). Among the oxidants, tetra- $n$-alkylammonium periodates are commonly employed for these HDA reactions, however, the removal of the tetra- $n$-alkylammonium salts, massively gener- ated in these reactions, is often complicated [2-5]. Although the Swern-Moffat oxidation [6], Dess-Martin oxidation [7], and metal-mediated/catalyzed oxidation reactions [8-12] are known as alternative methods $[13,14]$, these methods suffer from a narrow scope and/or low product yields. Furthermore, in the cases where these oxidation methods are inapplicable, a twostep procedure based on the liberation of the acylnitroso species by thermolysis of anthracenyl cycloadducts (route b) is widely used $[15,16]$. Therefore, there is a need to develop novel oxidation methods of hydroxamic acids for HDA reactions. 


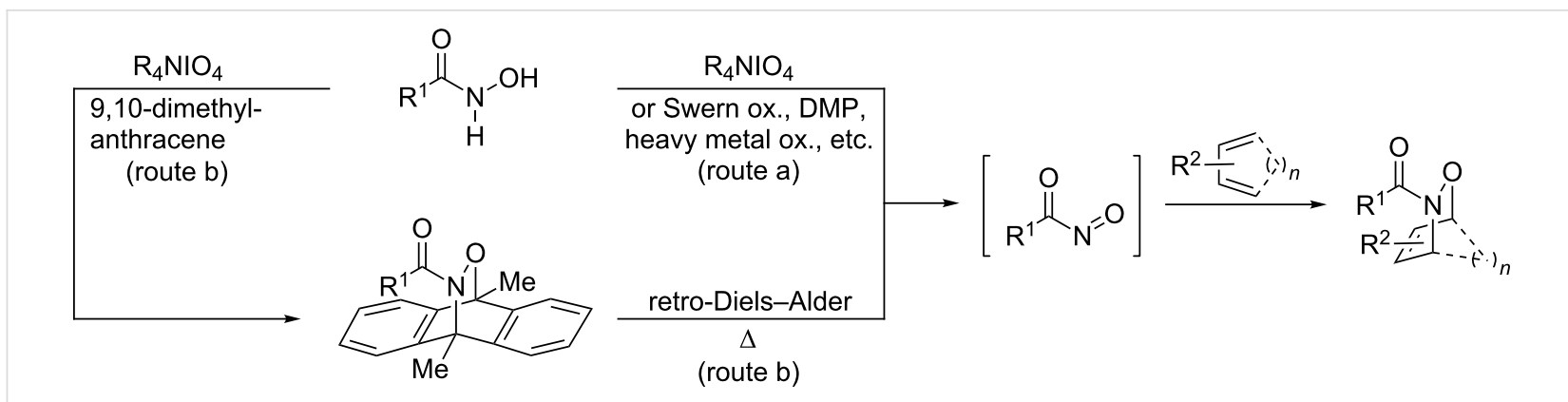

Scheme 1: Hetero-Diels-Alder (HDA) reactions of $\mathrm{N}$-acylnitroso species.

As part of our research on the syntheses of heterocycles by iodine(III)-mediated/catalyzed oxidative cycloaddition reactions [17-19], we have found that iodine(III) reagents are effective in the oxidation of $\mathrm{N}-\mathrm{O}$ bonds of oximes in the cycloaddition reaction of in situ formed nitrile oxides [20,21]. Although Adam and Bottke's group have demonstrated that (diacetoxyiodo)benzene (DIB) and iodosylbenzene are applicable to the ene reactions of acylnitroso species derived from hydroxamic acids [22], the iodine(III)-mediated oxidative cycloaddition reaction of hydroxamic acids with dienes is still unknown. Herein, we report the HDA reaction of acylnitroso species generated from hydroxamic acids by [bis(trifluoroacetoxy)iodo]benzene (BTI) or DIB. The present method could be applied to HDA reactions with not only simple dienes but also with masked $o$-benzoquinones (MOBs) generated by the oxidative dearomatization of guaiacols.

\section{Results and Discussion}

Our initial studies commenced with the screening of solvents and I(III) reagents for the oxidative cycloaddition reaction of hydroxamic acid $\mathbf{1 a}$ with 1,3-cyclohexadiene (2a, Table 1). In the presence of BTI ( 1.5 equiv), in polar solvents such as methanol, tetrahydrofuran (THF), acetonitrile, and ethyl acetate (Table 1, entries 1-4), or in organochlorine solvents such as chloroform, dichloroethane (DCE), and dichloromethane (DCM, Table 1, entries 6-8), the HDA reactions smoothly

Table 1: Screening of I(III) reagents and solvents for HDA reaction of 1a with 2 a.

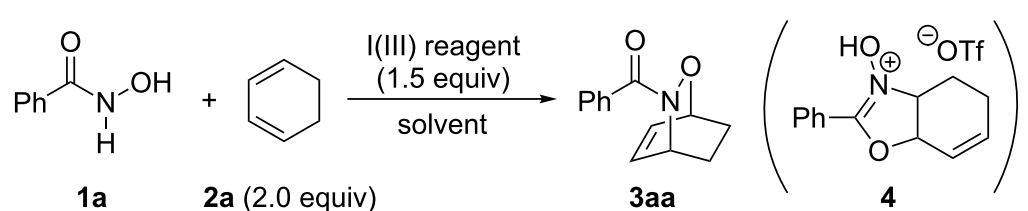<smiles>[R]C(=O)O[I](OC([R])=O)(c1ccc(Br)cc1)c1ccc(O)c(C(=O)O)c1</smiles>

\begin{tabular}{llllll}
\hline entry & I(III) reagent & solvent & temp. $\left({ }^{\circ} \mathrm{C}\right)$ & time $(\mathrm{h})$ & 3aa $(\%)^{\mathrm{a}}$ \\
\hline 1 & $\mathrm{BTI}$ & $\mathrm{MeOH}$ & $\mathrm{rt}$ & 24 & 78 \\
2 & $\mathrm{BTI}$ & $\mathrm{THF}$ & $\mathrm{rt}$ & 24 & 85 \\
3 & $\mathrm{BTI}$ & $\mathrm{MeCN}$ & $\mathrm{rt}$ & 24 & 81 \\
4 & $\mathrm{BTI}$ & $\mathrm{EtOAC}$ & $\mathrm{rt}$ & 24 & 89 \\
5 & $\mathrm{BTI}$ & heptane & $\mathrm{rt}$ & 24 & 41 \\
6 & $\mathrm{BTI}$ & $\mathrm{CHCl}$ & $\mathrm{rt}$ & 24 & 89 \\
7 & $\mathrm{BTI}$ & $\mathrm{DCE}$ & $\mathrm{rt}$ & 24 & 89 \\
8 & $\mathrm{BTI}$ & $\mathrm{DCM}$ & $\mathrm{rt}$ & 1 & 98 \\
9 & $\mathrm{BTI}$ & $\mathrm{DCM}$ & $\mathrm{rt}$ & 1 & 98 \\
10 & $\mathrm{DIB}$ & $\mathrm{DCM}$ & $\mathrm{rt}$ & 1 & 96 \\
11 & PhIO & $\mathrm{DCM}$ & $\mathrm{rt}$ & 1 & 90 \\
12 & $\mathrm{IBA}-\mathrm{OTf}$ & $\mathrm{DCM}$ & 40 & 24 & $0\left(\mathbf{4}: 85^{\mathrm{c}}\right)$ \\
13 & IBA-OTf & DCM & -40 & 24 & 80 \\
\hline
\end{tabular}

alsolated yields. ${ }^{b} 1.1$ equiv. ${ }^{c}$ Yield was determined by ${ }^{1} \mathrm{H}$ NMR analysis. 
proceeded at room temperature within $24 \mathrm{~h}$ to give the desired endo-cycloadduct 3aa in 78-98\% yield. In particular, the reaction in DCM led to a full conversion to 3aa within $1 \mathrm{~h}$ (Table 1, entry 8 ) and a reduced amount of BTI (even 1.1 equiv) brought about the similar result (3aa: 98\%, Table 1, entry 9). Although replacing BTI with DIB or iodosylbenzene (1.5 equiv) afforded the HDA adducts $3 \mathbf{a a}$ in 96 and $90 \%$ yields, respectively (Table 1, entries 10 and 11), BTI showed better results (Table 1, entries 8 and 9). On the other hand, the use of IBA-OTf, which was effective in the oxidative cycloaddition reaction of oximes [20,21], gave nitrone-trifluoromethanesulfonic acid (TfOH) complex 4 at $40{ }^{\circ} \mathrm{C}$ for $24 \mathrm{~h}$ in $85 \%$ yield (Table 1, entry 12 ). Furthermore, when IBA-OTf was employed at lower temperature $\left(-40^{\circ} \mathrm{C}\right)$, the HDA adduct $3 \mathbf{a a}$ was obtained in $80 \%$ yield (Table 1 , entry 13). These results suggest that the initially formed $\mathbf{3 a a}$ is converted into $\mathbf{4}$ by TfOH derived from IBAOTf. To test this hypothesis, the oxazine 3aa was treated with $\mathrm{TfOH}$ in DCM at $40{ }^{\circ} \mathrm{C}$ for $18 \mathrm{~h}$ and afforded 4 quantitatively.
Furthermore, the TfOH-mediated formation of nitrone from such HDA adducts has been reported [23]. It should be mentioned that the structures of $\mathbf{3 a a}$ and $\mathbf{4}$ were determined by single crystal X-ray analysis [24].

Next, we investigated the oxidative cycloaddition reactions of hydroxamic acids $\mathbf{1 a}-\mathbf{c}$ with various dienes $\mathbf{2}$ under the optimal conditions (Table 2). Similarly to the benzoyl derivative 1a, the carbamate analogues $\mathbf{1 b}\left(\mathrm{R}^{1}=\mathrm{OBn}\right)$ and $\mathbf{1 c}\left(\mathrm{R}^{1}=\mathrm{O} t-\mathrm{Bu}\right)$ reacted with 1,3-cyclohexadiene (2a, 2 equiv) in the presence of BTI (1.5 equiv) [25] at room temperature for $1 \mathrm{~h}$ to give the corresponding HDA adducts 3ba and 3ca in 99 and 85\% yields, respectively (Table 2, entries 1-3). However, in the reactions of $\mathbf{1 a}-\mathbf{c}$ with more reactive dienes such as cyclopentadiene (2b) and 9,10-dimethylanthracene (2c), DIB (1.1 equiv) showed better results, thereby affording the HDA adducts $\mathbf{3} \mathbf{a b}$ and 3ac-3cc in $69-82 \%$ yields (Table 2 , entries $4-7$ ). In case of less reactive dienes such as 2,3-dimethyl-1,3-butadiene (2d) and

Table 2: BTI or DIB-mediated oxidative HAD reactions of $1 \mathrm{a}-\mathrm{c}$ with various dienes.

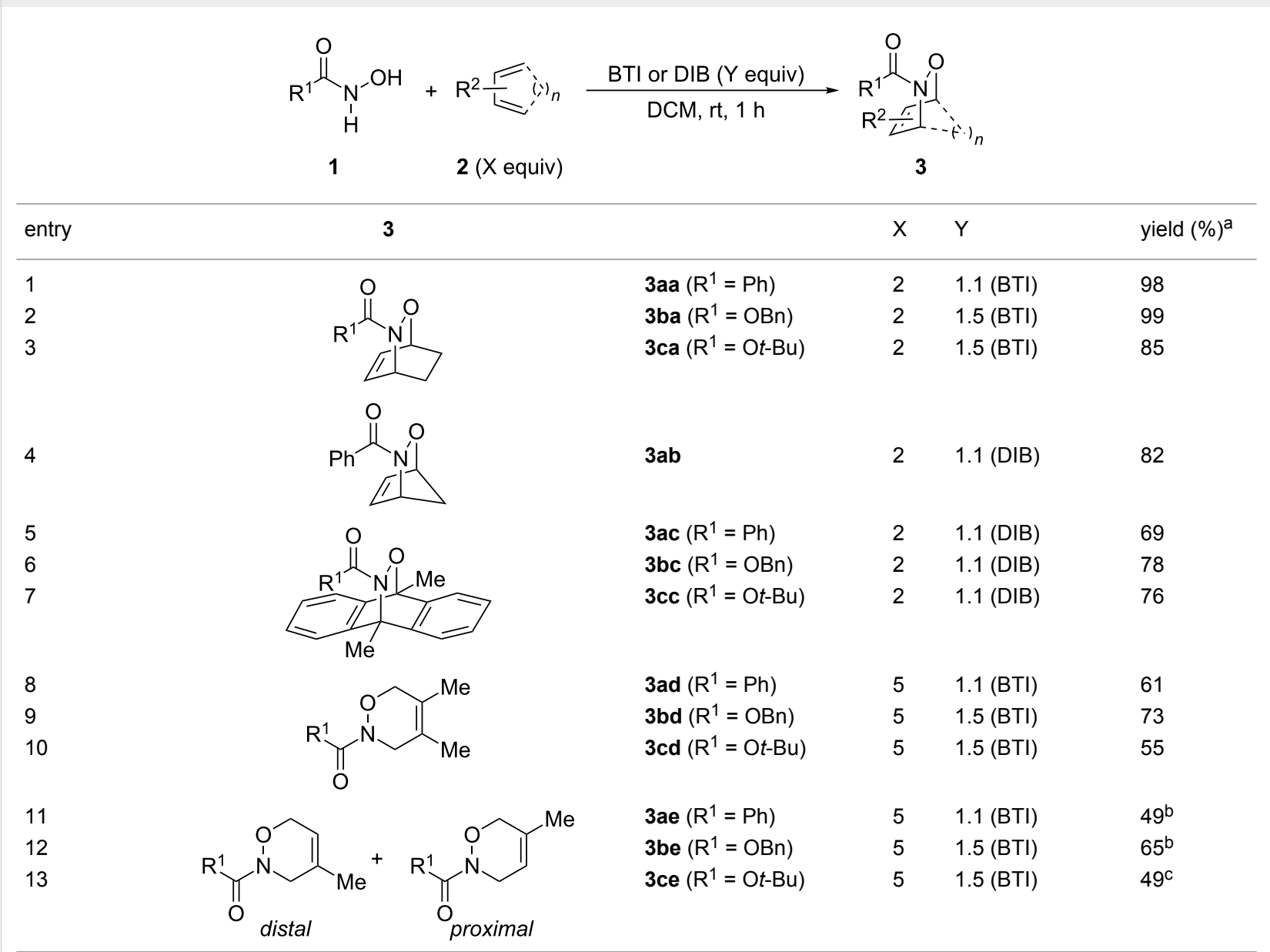

alsolated yields. ${ }^{b}$ Distal:proximal $=2: 1 .{ }^{c}$ Distal: proximal $=1: 1$. 
isoprene (2e), by the use of BTI (1.1 or 1.5 equiv) [25] along with the increase in the amount of diene to 5 equiv, the HDA adducts $\mathbf{3 a d}-\mathbf{3 c d}$ and $\mathbf{3 a e}-\mathbf{3 c e}$ were obtained in moderate to good yields (3ad-3cd: 55-73\%, 3ae-3ce: $49-65 \%$; Table 2 , entries 8-13). The HDA adducts 3ae-3ce derived from $\mathbf{2 e}$ were isolated as mixtures of regioisomers (distal:proximal $=2: 1$ or 1:1 as determined by ${ }^{1} \mathrm{H}$ NMR analysis).

As a further application of the iodine(III)-mediated oxidative cycloaddition reactions, the present method was extended to HDA reactions with masked $o$-benzoquinones (MOBs) generated by the oxidative dearomatization [26-29] of guaiacols with methanol (Scheme 2). Liao's and other groups have developed the DA reactions with MOBs as dienes [30-33], which recently were employed in the HDA reactions of acylnitroso species [34]. However, in the HDA reactions with MOBs, the oxidation of the hydroxamic acids to the acylnitroso species requires other oxidants such as tetra- $n$-alkylammonium periodates. To our delight, the sole use of DIB in a mixed solvent of DCM and methanol gave the endo-cycloadduct $6 \mathbf{a a}$ as a single regioisomer in $84 \%$ yield starting from hydroxamic acid 1a and guaiacol (5a, Scheme 2). The structure of 6aa was determined by single crystal X-ray analysis [24]. It should be mentioned that a slow addition of $\mathbf{1 a}$ to the solution of $\mathbf{5 a}$ and DIB over a period of $3 \mathrm{~h}$ was essential for an effective formation of 6aa. Furthermore, this procedure could be applied successfully to the oxidative cycloaddition reaction of $1 \mathbf{a}$ with various guaiacols $\mathbf{5 b}-\mathbf{g}$ and to the reaction of hydroxamic acids $\mathbf{1 b}$ and $\mathbf{1 c}$ with 5a. The corresponding products $6 \mathbf{a b}-\mathbf{6 a g}, \mathbf{6 b a}$, and $\mathbf{6 c a}$ were obtained with complete regioselectivities in $70-89 \%$ yields, albeit low to moderate yields in cases of the bromo- substituted 6ad (53\%) and methoxycarbonyl-substituted 6ae (28\%).

In most cases of the attempted reactions of $\mathbf{1 a}$ with simple dienes or guaiacols, benzoyl anhydride was detected as a byproduct. Since benzoyl anhydride is known to be formed via the dimerization of benzoylnitroso compounds [35], these results suggest that acylnitroso species would be generated from 1a by iodine(III) reagents. Therefore, the high endo selectivities of 1,2-oxadines 3aa-3ca, 3ab, and $\mathbf{6}$ would depend on the avoidance of electrostatic repulsion between the nitrogen lone pairs of acylnitroso species with $\pi$-electrons of the electron-rich dienes in the exo transition states (exo-lone-pair effect) [36]. Furthermore, the regioselectivities observed for 3ae, 3be $[12,36]$, and $\mathbf{6}[34]$ are in consistency with experimental data as well as the results of FMO and DFT calculations. The decline in regioselectivity of 3ce may be due to steric repulsion between the sterically hindered tert-butyloxycarbonyl group in $\mathbf{1 c}$ with the 2-methyl substituent of isoprene.

\section{Conclusion}

In summary, we demonstrated that BTI and DIB promote the formation of acylnitroso species from hydroxamic acids in the presence of various simple dienes to give the corresponding HDA adducts in moderate to high yields. The present method could be applied to a one-pot reaction involving the generation of MOBs by the dearomatization of guaiacols followed by the HDA reactions of acylnitroso species with MOBs as dienes. Our findings provide an extended scope of dienes for the HDA reactions and HDA reactions of acylnitroso species with MOBs using single oxidants.

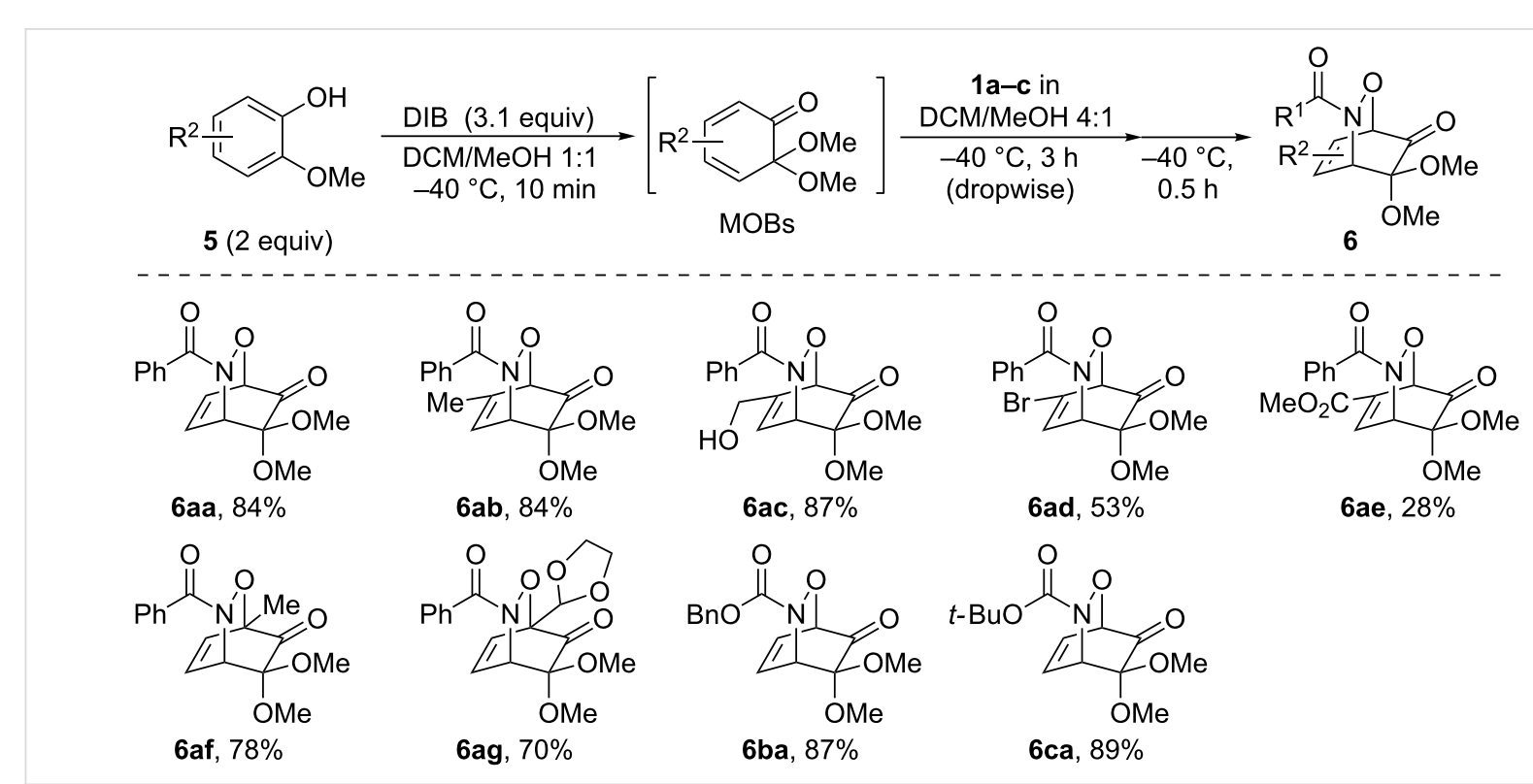

Scheme 2: DIB-mediated oxidative HDA reactions of $1 \mathrm{a}-\mathrm{c}$ with various guaiacols. 


\section{Supporting Information}

\section{Supporting Information File 1}

Experimental section.

[https://www.beilstein-journals.org/bjoc/content/

supplementary/1860-5397-14-39-S1.pdf]

\section{Supporting Information File 2}

$\mathrm{X}$-ray structure of 3aa.

[https://www.beilstein-journals.org/bjoc/content/

supplementary/1860-5397-14-39-S2.cif]

\section{Supporting Information File 3}

$\mathrm{X}$-ray structure of 4 .

[https://www.beilstein-journals.org/bjoc/content/

supplementary/1860-5397-14-39-S3.cif]

\section{Supporting Information File 4}

X-ray structure of $6 \mathbf{a a}$.

[https://www.beilstein-journals.org/bjoc/content/

supplementary/1860-5397-14-39-S4.cif]

\section{Acknowledgements}

This work was partially supported by JSPS Grants-in-Aid for Scientific Research (C) (Grant No 15K07852) and by JSPS Fund for the Promotion of Joint International Research (Grant No 16KK0199). V.V.Z. and A.Y. are also thankful to Tomsk Polytechnic University (VIU-316/2017).

\section{ORCID ${ }^{\circledR}$ iDs}

Viktor V. Zhdankin - https://orcid.org/0000-0002-0315-8861

Akio Saito - https://orcid.org/0000-0002-8291-2059

\section{References}

1. Bodnar, B. S.; Miller, M. J. Angew. Chem., Int. Ed. 2011, 50, 5630-5647. doi:10.1002/anie.201005764

2. Keck, G. E.; Fleming, S. A. Tetrahedron Lett. 1978, 19, 4763-4766 doi:10.1016/S0040-4039(01)85725-7

3. Kirby, G. W.; Sweeny, J. G. J. Chem. Soc., Perkin Trans. 11981 , 3250-3254. doi:10.1039/p19810003250

4. Krchňák, V.; Moellmann, U.; Dahse, H.-M.; Miller, M. J. J. Comb. Chem. 2008, 10, 94-103. doi:10.1021/cc700140h

5. Monbaliu, J.-C. M. R.; Cukalovic, A.; Marchand-Brynaert, J.; Stevens, C. V. Tetrahedron Lett. 2010, 51, 5830-5833. doi:10.1016/j.tetlet.2010.08.117

6. Martin, S. F.; Hartmann, M.; Josey, J. A. Tetrahedron Lett. 1992, 33, 3583-3586. doi:10.1016/S0040-4039(00)92508-5

7. Jenkins, N. E.; Ware, R. W., Jr.; Atkinson, R. N.; King, S. B. Synth. Commun. 2000, 30, 947-953. doi:10.1080/00397910008087108

8. Dao, L. H.; Dust, J. M.; Mackay, D.; Watson, K. N. Can. J. Chem. 1979, 57, 1712-1719. doi:10.1139/v79-274
9. Flower, K. R.; Lightfoot, A. P.; Wan, H.; Whiting, A. J. Chem. Soc., Perkin Trans. 1 2002, 2058-2064. doi:10.1039/B206430H

10. Iwasa, S.; Fakhruddin, A.; Tsukamoto, Y.; Kameyama, M.; Nishiyama, H. Tetrahedron Lett. 2002, 43, 6159-6161. doi:10.1016/S0040-4039(02)01277-7

11. Porter, D.; Poon, B. M.-L.; Rutledge, P. J. Beilstein J. Org. Chem. 2015, 11, 2549-2556. doi:10.3762/bjoc. 11.275

12. Lewis, R. B.; Read de Alaniz, J. Tetrahedron 2017, 73, 4045-4051. doi:10.1016/j.tet.2016.11.046

13. Quadrelli, P.; Invernizzi, A. G.; Caramella, P. Tetrahedron Lett. 1996, 37, 1909-1912. doi:10.1016/0040-4039(96)00151-7

14. Davey, M. H.; Lee, V. Y.; Miller, R. D.; Marks, T. J. J. Org. Chem. 1999 , 64, 4976-4979. doi:10.1021/jo990235x

15. Keck, G. E.; Webb, R. R.; Yates, J. B. Tetrahedron 1981, 37, 4007-4016. doi:10.1016/S0040-4020(01)93275-2

16. Monbaliu, J.-C.; Marchand-Brynaert, J.; Peeters, D. Tetrahedron Lett. 2009, 50, 2555-2558. doi:10.1016/j.tetlet.2009.03.062

17. Saito, A. ARKIVOC 2017, No. (i), 84-98. doi:10.24820/ark.5550190.p009.965

18. Yagyu, T.; Takemoto, Y.; Yoshimura, A.; Zhdankin, V. V.; Saito, A. Org. Lett. 2017, 19, 2506-2509. doi:10.1021/acs.orglett.7b00742

19. Baba, T.; Takahashi, S.; Kambara, Y.; Yoshimura, A.; Nemykin, V. N.; Zhdankin, V. V.; Saito, A. Adv. Synth. Catal. 2017, 359, 3860-3864. doi:10.1002/adsc.201700934

20. Yoshimura, A.; Nguyen, K. C.; Klasen, S. C.; Saito, A.; Nemykin, V. N.; Zhdankin, V. V. Chem. Commun. 2015, 51, 7835-7838. doi:10.1039/C5CC02009C

21. Yoshimura, A.; Nguyen, K. C.; Rohde, G. T.; Saito, A.; Yusubov, M. S.; Zhdankin, V. V. Adv. Synth. Catal. 2016, 358, 2340-2344. doi:10.1002/adsc.201600331

22. Adam, W.; Bottke, N.; Krebs, O.; Saha-Möller, C. R. Eur. J. Org. Chem. 1999, 1963-1965. doi:10.1002/(SICI)1099-0690(199908)1999:8<1963::AID-EJOC1963>3 .0.CO;2-3

23. Bodnar, B. S.; Miller, M. J. Tetrahedron Lett. 2009, 50, 796-798. doi:10.1016/j.tetlet.2008.11.120

24. CCDC-1813170 (3aa), CCDC-1812653 (4), and CCDC-1812654 (6aa) contain the supplementary crystallographic data for this paper. These data can be obtained free of charge from The Cambridge Crystallographic Data Centre via http://www.ccdc.cam.ac.uk/data_request/cif.

25. In the reactions of the carbamate analogues $\mathbf{1 b}$ and $\mathbf{1 c}$ using 1.1 equiv of $\mathrm{BTI}$, the starting materials were recovered in $10-15 \%$.

26. Liao, C.-C.; Peddinti, R. K. Acc. Chem. Res. 2002, 35, 856-866. doi:10.1021/ar000194n

27. Kita, Y.; Fujioka, H. Pure Appl. Chem. 2007, 79, 701-713. doi:10.1351/pac200779040701

28. Pouységu, L.; Deffieux, D.; Quideau, S. Tetrahedron 2010, 66, 2235-2261. doi:10.1016/j.tet.2009.12.046

29. Turner, C. D.; Ciufolini, M. A. ARKIVOC 2011, No. (i), 410-428.

30. Lai, C.-H.; Shen, Y.-L.; Liao, C.-C. Synlett 1997, 1351-1352. doi:10.1055/s-1997-1053

31. Lai, C.-H.; Shen, Y.-L.; Wang, M.-N.; Rao, N. S. K.; Liao, C.-C. J. Org. Chem. 2002, 67, 6493-6502. doi:10.1021/jo020171h

32. Arjona, O.; Medel, R.; Plumet, J.; Herrera, R.; Jiménez-Vázquez, H. A.; Tamariz, J. J. Org. Chem. 2004, 69, 2348-2354. doi:10.1021/jo030307r

33. Deffieux, D.; Fabre, I.; Titz, A.; Léger, J.-M.; Quideau, S. J. Org. Chem. 2004, 69, 8731-8738. doi:10.1021/jo048677i 
34. Lu, P.-H.; Yang, C.-S.; Devendar, B.; Liao, C.-C. Org. Lett. 2010, 12, 2642-2645. doi:10.1021/ol100840n

35. Corrie, J. E. T.; Kirby, G. W.; Mackinnon, J. W. M.

J. Chem. Soc., Perkin Trans. 1 1985, 883-886. doi:10.1039/p19850000883

36. Leach, A. G.; Houk, K. N. J. Org. Chem. 2001, 66, 5192-5200. doi:10.1021/jo0104126

\section{License and Terms}

This is an Open Access article under the terms of the Creative Commons Attribution License

(http://creativecommons.org/licenses/by/4.0), which permits unrestricted use, distribution, and reproduction in any medium, provided the original work is properly cited.

The license is subject to the Beilstein Journal of Organic Chemistry terms and conditions:

(https://www.beilstein-journals.org/bjoc)

The definitive version of this article is the electronic one which can be found at: doi:10.3762/bjoc. 14.39 